\title{
Types of Glaucoma and Associated Comorbidities Among Patients at King Abdulaziz Medical City, Jeddah
}

Karim Talaat ${ }^{1}$, Obada T. Fathi ${ }^{2}$, Saeed M. Alamoudi ${ }^{2}$, Muhanad G. Alzahrani ${ }^{2}$, Rayan M. Mukhtar ${ }^{2}$, Muhammad A. Khan 3, 4, 5

1. Vitreoretinal Surgery - Department of Ophthalmology, King Abdulaziz Medical City, Ministry of National Guard Health Affairs / King Saud bin Abdulaziz University for Health Sciences, Jeddah, SAU 2. College of Medicine, King Saud bin Abdulaziz University for Health Sciences, Jeddah, SAU 3. Medical Education, College of Medicine, King Saud bin Abdulaziz University for Health Sciences, Jeddah, SAU 4. Research, King Abdullah International Medical Research Center, Jeddah, SAU 5. College of Medicine, King Abdulaziz Medical City, Jeddah, SAU

Corresponding author: Obada T. Fathi, obadafathi@gmail.com

\section{Abstract}

\section{Aim}

To identify the types of glaucoma and associated comorbidities among patients attending the ophthalmology clinic at King Abdulaziz Medical City (KAMC) in Jeddah.

\section{Methods}

A cross-sectional study that included all glaucoma patients at KAMC in Jeddah between June 1st, 2016 and November 30th, 2020. Data were collected through retrospective chart review from the electronic medical record system (BestCare) and utilized a structured data collection sheet.

\section{Results}

A total of 283 patients met the inclusion criteria. The most common type was primary open-angle glaucoma (POAG; 53\%) followed by secondary glaucomas (SG; 26.5\%) then childhood glaucoma and primary angleclosure glaucoma (CG, PACG; 7.4\%). The majority of secondary glaucoma cases were due to neovascular glaucoma (NVG; 44.9\%), followed by phacomorphic glaucoma (17.9\%) and phacolytic glaucoma (10.3\%). Hypertension (60.8\%) and diabetes (58.3\%) were the most prevalent systematic comorbidities, and cataract $(49.1 \%)$ was the most prevalent ocular comorbidity.

\section{Conclusion}

POAG was the most common glaucoma type, followed by SG, CG, and PACG. Among secondary glaucoma types, neovascular glaucoma was found to be the most common subtype. Hypertension was the most

Review began 05/09/2021 Review ended 05/30/2021 Published 06/10/2021

\section{(c) Copyright 2021}

Talaat et al. This is an open access article distributed under the terms of the Creative Commons Attribution License CC-BY 4.0., which permits unrestricted use, distribution, and reproduction in any medium, provided the original author and source are credited. prevalent comorbid condition.

Categories: Ophthalmology

Keywords: primary open angle glaucoma, open angle glaucoma, neovascular glaucoma, medical comorbidities, hospital epidemiology, prevalence study

\section{Introduction}

Blindness is one of the major public health concerns, and as the size of the population increases, this issue will exert a huge burden on public health [1]. Glaucoma is a group of eye diseases that can result in irreversible visual field loss and degenerative optic neuropathy. Usually, it is asymptomatic at early stages, but permanent visual impairment can ensue at late stages [2]. Thus, early checkups and diagnosis followed by the appropriate treatment are crucial [3,4]. In addition, several risk factors are associated with glaucoma, including age, hypertension, and refractive errors [5].

Glaucoma is regarded as the leading cause of irreversible blindness and the second leading cause of blindness worldwide by the World Health Organization (WHO) [6,7]. It is estimated that the pooled worldwide prevalence of glaucoma between the ages of $40-80$ is $3.54 \%$ [6]. Moreover, the global prevalence of primary open-angle glaucoma (POAG) and primary angle-closure glaucoma (PACG) is $3.05 \%$ and $0.50 \%$, respectively. POAG was highest among patients of African ancestry, while those of Asian ancestry had the highest prevalence of PACG [6]. Projections for the worldwide burden of glaucoma have estimated that glaucoma prevalence will rise by $74 \%$ from 2013 to 2040, which accounts for 111.8 million patients, most of whom are in Asia and Africa [6]. However, there is insufficient evidence regarding the prevalence of glaucoma and its causes in the Saudi population [7]. The latest estimate on the prevalence of glaucoma in Saudi Arabia is 5.6\%, based on a 2019 study in Riyadh governorate which involved 940 subjects across six 


\section{Cureus}

primary health care facilities [4].

Visual impairment continues to be a major public health concern with a substantial impact on all aspects of quality of life, including physical functioning, emotional distress, and socioeconomic loss [8]. The paucity of data on types of glaucoma and their risk factors in the Saudi population highlights the importance of such studies, which allow for the planning and implementation of blindness prevention programs according to the needs of different populations. This study aims to identify the common causes of glaucoma and associated comorbidities among patients attending the ophthalmology clinic at King Abdulaziz Medical City (KAMC) in Jeddah.

\section{Materials And Methods}

This cross-sectional study was conducted at KAMC in Jeddah, Saudi Arabia. It included patients diagnosed with glaucoma attending general ophthalmology clinics between June 1st, 2016 and November 30th, 2020, using a consecutive sampling technique. Patients with other types of optic neuropathy were excluded from the study. A retrospective chart review was conducted using electronic medical records and a structured data collection sheet. The data collection sheet consisted of socio-demographic variables like age, gender, and BMI. Moreover, clinical variables such as glaucoma type and etiology, visual acuity, treatments, and comorbidities, were recorded. Using the International Council of Ophthalmology classification, the best corrected visual acuity (BCVA) was categorized into normal vision as 6/6 - 6/7.5, near-normal vision as 6/9.5 - 6/18, moderate vision loss as 6/21 - 6/48, severe vision loss as 6/60 - counting fingers (CF), near-blindness is hand motion (HM) - light perception (LP), and blindness as no light perception (NLP) [9]. For children from 2 months to 24 months, visual acuity was assessed by fixating eyes on an object and following it. The visual acuity of infants aged less than one month was assessed by blinking response to light [9]. Variables were represented as median and interquartile ranges. The data were compiled in Microsoft Excel 2016 and analyzed using IBM Statistical Package for the social sciences (SPSS) version 25.0 (IBM Corp., Armonk, NY, USA). Qualitative variables were presented using descriptive statistics in the form of categories and summarized as frequencies and percentages. Data comparison was interpreted using the Chi-square test and Fisher exact test, and a p-value that is less than 0.05 was considered significant.

All patients' data were kept confidential, and ethical approval was obtained from the Institutional Review Board at King Abdullah International Medical Research Centre (KAIMRC), National Guard Health Affairs (NGHA), Jeddah, Saudi Arabia (Reference number: JED-21-427780-3866, January 26th, 2021).

\section{Results}

A total of 283 patients fulfilled the inclusion criteria, 133 (47\%) of which were males, and 150 (53\%) were females. Our sample noted that $59.9 \%$ of the patients had bilateral disease, while $40 \%$ had unilateral disease $(\mathrm{p}<0.001)$. The median (IQR) for age was 66 years $(57-74)$, ranging from two months to 101 years old, BMI $29 \mathrm{~kg} / \mathrm{m}^{2}$ (25-33), and intraocular pressure of $16 \mathrm{mmHg}(13-20)$ in both eyes (Table 1).

\begin{tabular}{|c|c|c|}
\hline & Median & IQR \\
\hline Age (months) & 66 & $57-74$ \\
\hline BMI (Body Mass Index) & 29 & $25-33$ \\
\hline Right eye IOP (Intra-Ocular Pressure) & 16 & $13-20$ \\
\hline Left eye IOP (Intra-Ocular Pressure) & 16 & $13-20$ \\
\hline
\end{tabular}

TABLE 1: Proportions of study sample by age, BMI, and IOP.

The most common glaucoma types were primary open-angle glaucoma (POAG; 53\%) followed by secondary glaucoma (SG; 26.5\%), then childhood glaucoma and primary angle-closure glaucoma (CG, PACG; 7.4\%). Normal-tension glaucoma (NTG) accounted for $2.5 \%$, absolute (unspecified) glaucoma accounted for $2.1 \%$, and both juvenile and mixed mechanism glaucoma represented $0.7 \%$ and $0.4 \%$ of the sample, respectively (Figure 1). Additional data, including affected eye analysis, are shown in Table 2. 


\section{Cureus}

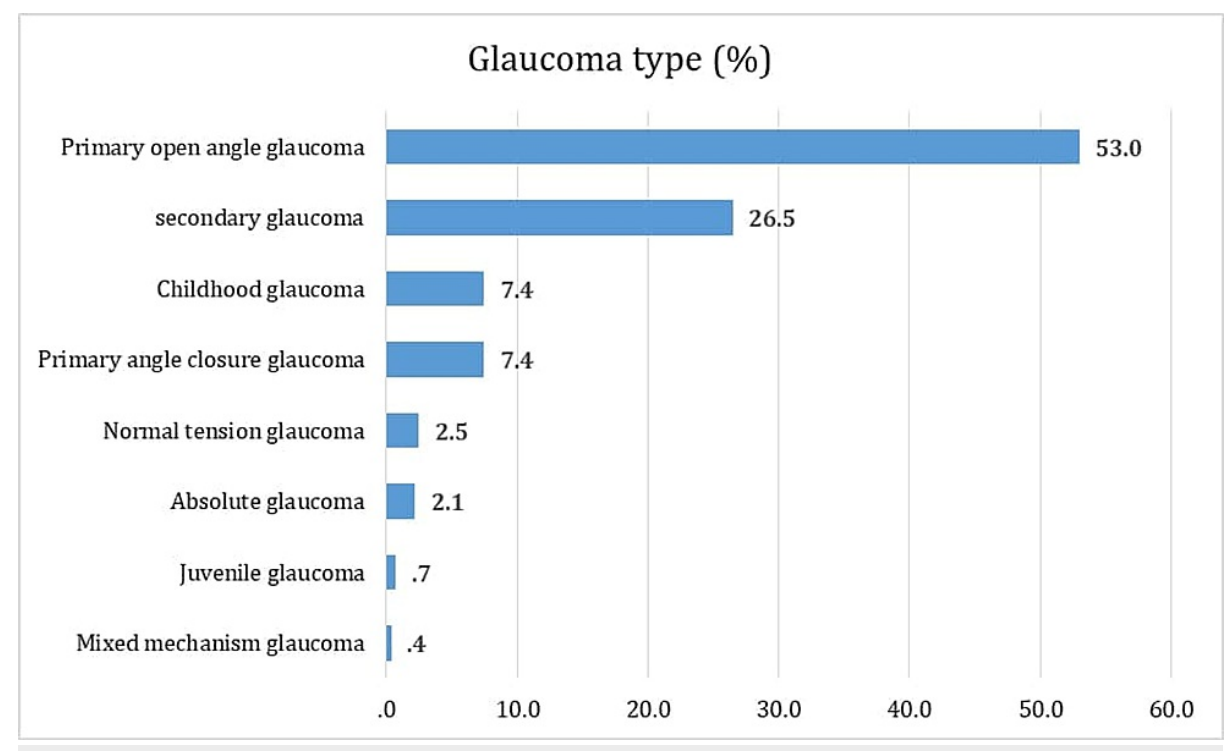

FIGURE 1: Distribution of glaucoma types

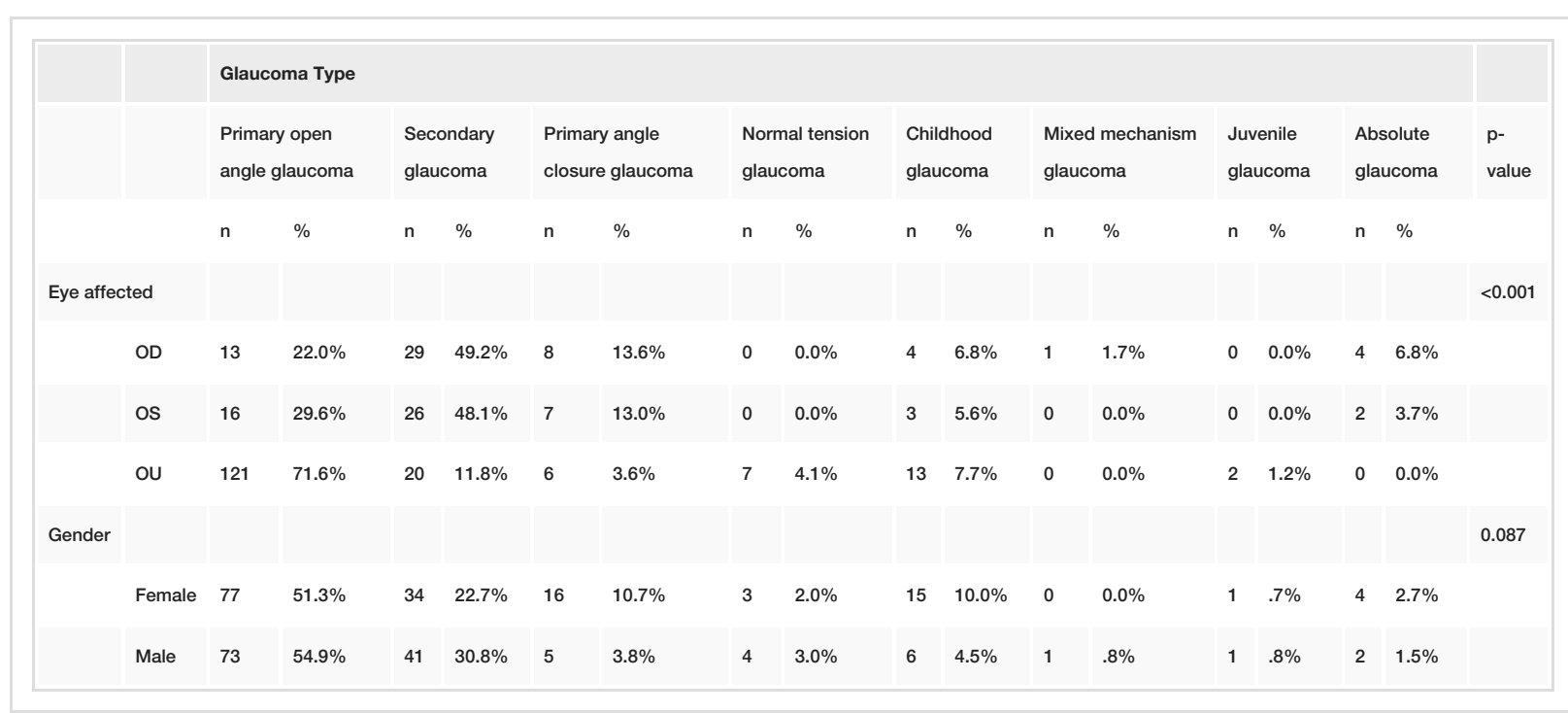

TABLE 2: Distribution of gender and affected eyes between glaucoma types

Oculus Dexter (OD) for the right eye, Oculus sinister (OS) for the left eye, Oculus Uterque (OU) for both eyes.

Further analysis of secondary glaucoma patients into subcategories revealed that most cases were due to neovascular glaucoma (NVG, 44.9\%). Other types of secondary glaucoma included phacomorphic glaucoma (17.9\%) and phacolytic glaucoma (10.3\%). Additional types of glaucoma that were seen less frequently included angle recession glaucoma (2.6\%), uveitis glaucoma (2.6\%), malignant glaucoma (2.6\%), posttraumatic glaucoma (1.3\%), and aphakic glaucoma (1.3\%) (Figure 2). Additional data about secondary glaucoma types are shown in Table 3. 


\section{Cureus}

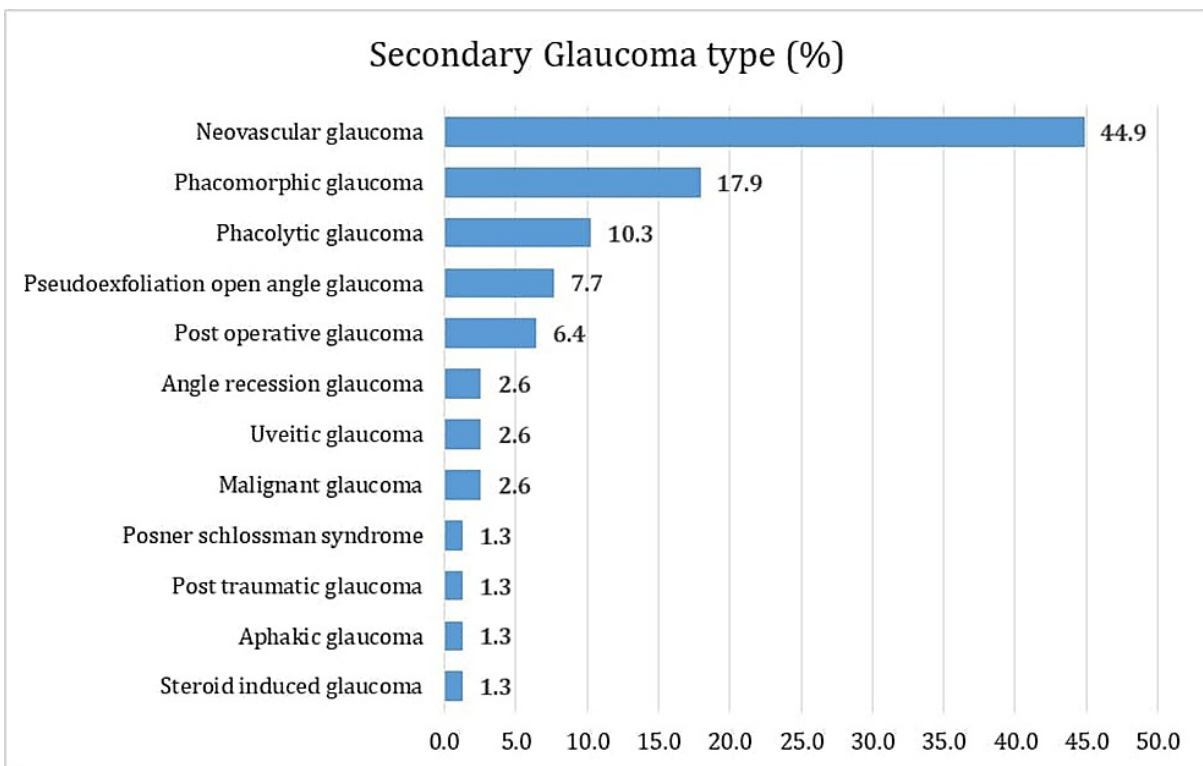

FIGURE 2: Distribution of secondary glaucoma types

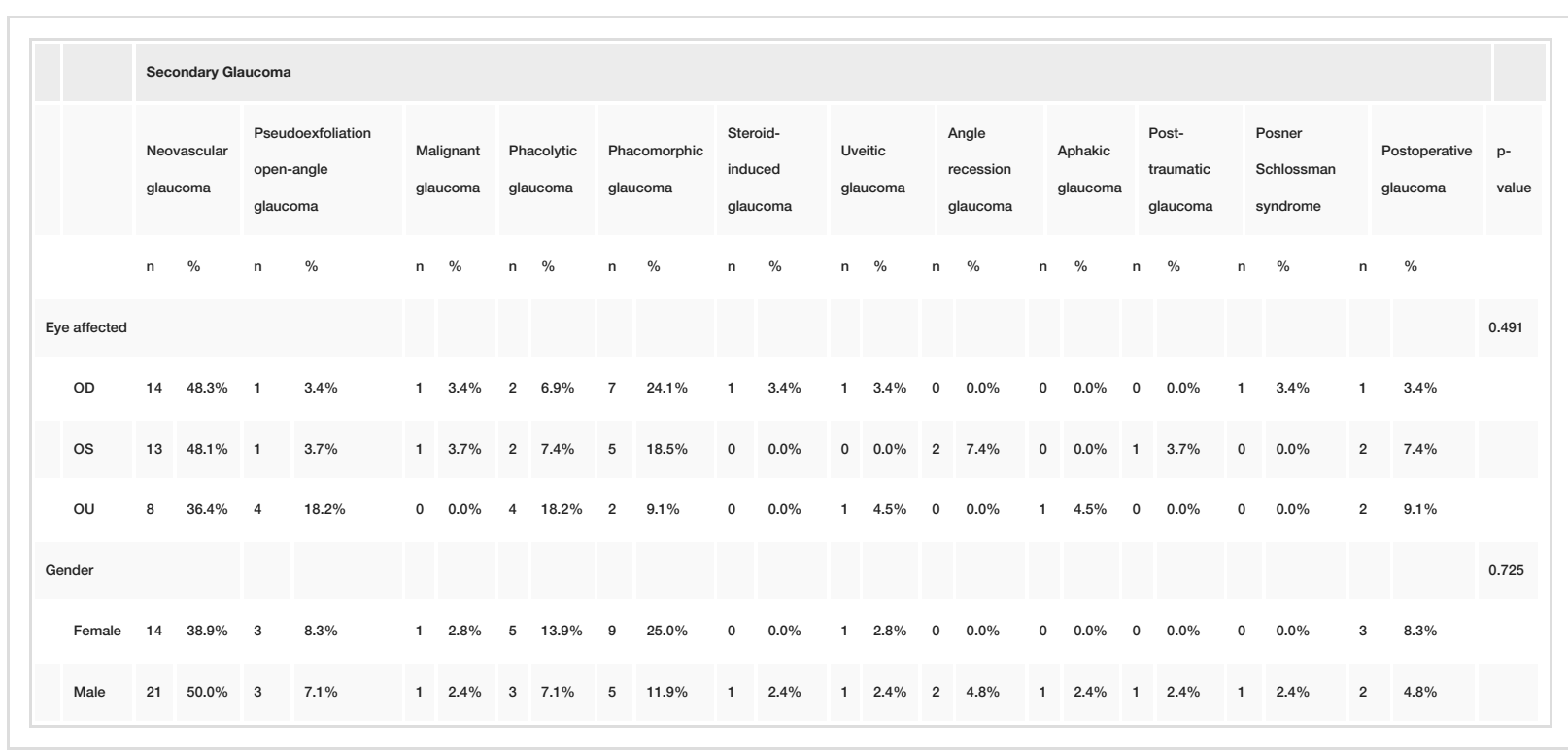

TABLE 3: Distribution of gender and affected eyes among patients suffering from secondary glaucoma

Oculus Dexter (OD) for the right eye, Oculus sinister (OS) for the left eye, Oculus Uterque (OU) for both eyes.

The most common associated systematic comorbidities among patients diagnosed with glaucoma were hypertension (60.8\%), diabetes (58.3\%), obesity (43.1\%), and dyslipidemia (33.6\%). Cataract (49.1\%) was the most prevalent associated ocular comorbidity. Other comorbidities were also noted in glaucoma patients but were less frequent, such as ischemic heart disease (15.2\%), renal diseases (14.1\%), hypothyroidism, and cerebrovascular disease (10.6\%). Further details are shown in Figure 3. 


\section{Cureus}

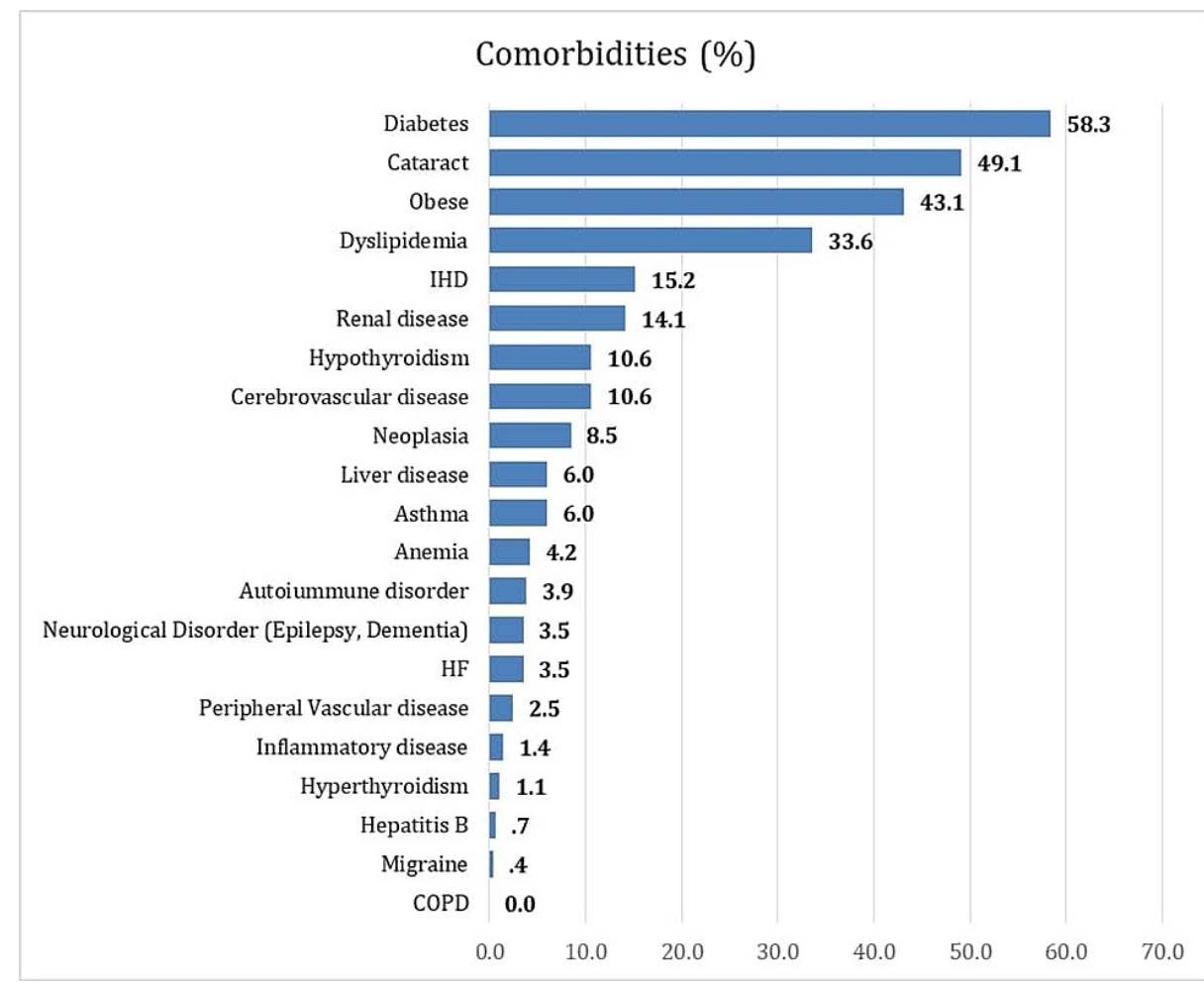

FIGURE 3: Prevalence of comorbidities among glaucoma patients

Ischemic Heart Disease (IHD), Heart Failure (HF), Chronic obstructive pulmonary disease (COPD).

Analysis of visual acuity showed that most patients had a moderate loss of visual acuity (26.87\%), followed by near-normal visual acuity (19.22\%), and followed by severe loss of visual acuity (18.15\%). Most of the children were able to fix and follow objects with their eyes $(0.8 \%)$ and blink to light $(0.7 \%)$, while only a few of them couldn't fix and follow objects (0.5\%). Details regarding visual acuity impairment are found in Table 4.

\begin{tabular}{|c|c|c|c|c|c|c|}
\hline & \multicolumn{2}{|c|}{ Rt VA } & \multicolumn{2}{|c|}{ Lt VA } & \multicolumn{2}{|c|}{ Total VA } \\
\hline & $\mathbf{n}$ & $\%$ & $\mathbf{n}$ & $\%$ & $\mathbf{n}$ & $\%$ \\
\hline Normal & 45 & 16.0 & 45 & 16.0 & 90 & 16.01 \\
\hline Near-normal & 53 & 18.9 & 55 & 19.6 & 108 & 19.22 \\
\hline Moderate & 75 & 26.7 & 76 & 27.0 & 151 & 26.87 \\
\hline Severe & 50 & 17.8 & 52 & 18.5 & 102 & 18.15 \\
\hline Near blindness & 19 & 6.8 & 20 & 7.1 & 39 & 6.94 \\
\hline Legal blindness & 39 & 13.9 & 33 & 11.7 & 72 & 12.81 \\
\hline Total & 281 & 100 & 281 & 100 & 562 & 100 \\
\hline
\end{tabular}

\section{TABLE 4: Visual acuity among glaucoma patients}

Visual acuity (VA), Right eye (Rt), Left eye (Lt)

Control of intraocular pressure was achieved by medical, laser, or surgical methods. In terms of medical therapy used in our sample, beta-blockers were the most commonly used agents (72\%), followed by carbonic anhydrase (CA) inhibitors (71.3\%). Prostaglandins and $\alpha 2$-agonists were used by $61.4 \%$ and $60.7 \%$ of patients, respectively. Moreover, laser peripheral iridotomy was utilized in $7.4 \%$, while cyclocryocoagulation was used in $4.9 \%$. Regarding surgical procedures, trabeculectomy was performed in $50.1 \%$ of patients. 
Further information is represented in Table 5 .

\begin{tabular}{|c|c|c|c|c|c|c|c|c|c|c|}
\hline & & \multicolumn{8}{|l|}{ Glaucoma Type } & \multirow[b]{2}{*}{$p$-value } \\
\hline & & $\begin{array}{l}\text { Primary open } \\
\text { angle glaucoma }\end{array}$ & $\begin{array}{l}\text { Secondary } \\
\text { glaucoma }\end{array}$ & $\begin{array}{l}\text { Primary angle } \\
\text { closure glaucoma }\end{array}$ & $\begin{array}{l}\text { Normal tension } \\
\text { glaucoma }\end{array}$ & $\begin{array}{l}\text { Childhood } \\
\text { glaucoma }\end{array}$ & $\begin{array}{l}\text { Mixed mechanism } \\
\text { glaucoma }\end{array}$ & $\begin{array}{l}\text { Juvenile } \\
\text { glaucoma }\end{array}$ & $\begin{array}{l}\text { Absolute } \\
\text { glaucoma }\end{array}$ & \\
\hline & & $n(\%)$ & $n(\%)$ & $n(\%)$ & $n(\%)$ & $n(\%)$ & $n(\%)$ & $\mathrm{n}(\%)$ & $n(\%)$ & \\
\hline \multirow{2}{*}{ Prostaglandins } & No & $49(45)$ & $37(33.9)$ & $4(3.7)$ & $3(2.8)$ & $12(11)$ & $0(0)$ & $1(0.9)$ & $3(2.8)$ & \multirow{2}{*}{0.062} \\
\hline & Yes & 101(58) & $38(21.8)$ & $17(9.8)$ & $4(2.3)$ & $9(5.2)$ & $1(0.6)$ & $1(0.6)$ & $3(1.7)$ & \\
\hline \multirow{2}{*}{ B-Blockers } & No & $39(49.4)$ & $25(31.6)$ & $4(5.1)$ & $3(3.8)$ & $5(6.3)$ & $0(0)$ & $2(2.5)$ & $1(1.3)$ & \multirow{2}{*}{0.248} \\
\hline & Yes & 111(54.4) & $50(24.5)$ & $17(8.3)$ & 4(2) & $16(7.8)$ & $1(0.5)$ & $0(0)$ & $5(2.5)$ & \\
\hline \multirow{2}{*}{ a2-agonists } & No & $47(42.3)$ & $34(30.6)$ & $9(8.1)$ & $2(1.8)$ & $11(9.9)$ & $1(0.9)$ & $2(1.8)$ & $5(4.5)$ & \multirow{2}{*}{0.020} \\
\hline & Yes & 103(59.9) & $41(23.8)$ & $12(7)$ & $5(2.9)$ & $10(5.8)$ & $0(0)$ & $0(0)$ & $1(0.6)$ & \\
\hline \multirow{2}{*}{$\begin{array}{l}\text { Miotic agents } \\
\text { (cholinergic) }\end{array}$} & No & $150(53.4)$ & $75(26.7)$ & $19(6.8)$ & $7(2.5)$ & $21(7.5)$ & $1(0.4)$ & $2(0.7)$ & $6(2.1)$ & \multirow{2}{*}{0.001} \\
\hline & Yes & $0(0)$ & $0(0)$ & $2(100)$ & $0(0)$ & $0(0)$ & $0(0)$ & $0(0)$ & $0(0)$ & \\
\hline \multirow{2}{*}{ CA inhibitors } & No & $41(50.6)$ & $25(30.9)$ & $3(3.7)$ & $3(3.7)$ & $6(7.4)$ & $0(0)$ & $2(2.5)$ & $1(1.2)$ & \multirow{2}{*}{0.215} \\
\hline & Yes & $109(54)$ & 50(24.8) & $18(8.9)$ & $4(2)$ & $15(7.4)$ & $1(0.5)$ & $0(0)$ & $5(2.5)$ & \\
\hline \multirow{2}{*}{ TNF inhibitor } & No & $67(36.6)$ & $68(37.2)$ & $12(6.6)$ & $6(3.3)$ & $21(11.5)$ & $1(0.5)$ & $2(1.1)$ & $6(3.3)$ & \multirow{2}{*}{0.067} \\
\hline & Yes & $0(0)$ & $0(0)$ & $1(100)$ & $0(0)$ & $0(0)$ & $0(0)$ & $0(0)$ & $0(0)$ & \\
\hline \multirow{2}{*}{ Mannitol } & No & $150(53.2)$ & $75(26.6)$ & 20(7.1) & $7(2.5)$ & $21(7.4)$ & $1(0.4)$ & $2(0.7)$ & $6(2.1)$ & \multirow{2}{*}{0.085} \\
\hline & Yes & $0(0)$ & $0(0)$ & $1(100)$ & $0(0)$ & $0(0)$ & $0(0)$ & $0(0)$ & $0(0)$ & \\
\hline \multirow{2}{*}{ Trabeculoplasty } & No & $148(52.9)$ & $75(26.8)$ & $21(7.5)$ & $7(2.5)$ & $20(7.1)$ & $1(0.4)$ & $2(0.7)$ & $6(2.1)$ & \multirow{2}{*}{0.774} \\
\hline & Yes & $2(66.7)$ & $0(0)$ & $0(0)$ & $0(0)$ & $1(33.3)$ & $0(0)$ & $0(0)$ & $0(0)$ & \\
\hline \multirow{2}{*}{ Cyclo } & No & $149(53)$ & $75(26.7)$ & $20(7.1)$ & $7(2.5)$ & $21(7.5)$ & $1(0.4)$ & $2(0.7)$ & $6(2.1)$ & \multirow{2}{*}{0.573} \\
\hline & Yes & $1(50)$ & $0(0)$ & $1(50)$ & $0(0)$ & $0(0)$ & $0(0)$ & $0(0)$ & $0(0)$ & \\
\hline \multirow{2}{*}{ Cyclocryocoagulation } & No & $149(55.4)$ & 67(24.9) & $20(7.4)$ & $7(2.6)$ & $20(7.4)$ & $1(0.4)$ & $2(0.7)$ & $3(1.1)$ & \multirow{2}{*}{$<0.001$} \\
\hline & Yes & $1(7.1)$ & $8(57.1)$ & $1(7.1)$ & $0(0)$ & $1(7.1)$ & $0(0)$ & $0(0)$ & $3(21.4)$ & \\
\hline \multirow{2}{*}{$\begin{array}{l}\text { Pan-retinal } \\
\text { photocoagulation }\end{array}$} & No & $150(53.4)$ & $73(26)$ & $21(7.5)$ & $7(2.5)$ & $21(7.5)$ & $1(0.4)$ & $2(0.7)$ & $6(2.1)$ & \multirow{2}{*}{0.589} \\
\hline & Yes & $0(0)$ & $2(100)$ & $0(0)$ & $0(0)$ & $0(0)$ & $0(0)$ & $0(0)$ & $0(0)$ & \\
\hline \multirow{2}{*}{$\begin{array}{l}\text { Laser peripheral } \\
\text { iridotomy (YAG) }\end{array}$} & No & $148(56.6)$ & $71(27.1)$ & $7(2.7)$ & $7(2.7)$ & 20(7.6) & $1(0.4)$ & $2(0.8)$ & $6(2.3)$ & \\
\hline & Yes & $2(9.5)$ & $4(19)$ & $14(66.7)$ & $0(0)$ & $1(4.8)$ & $0(0)$ & $0(0)$ & $0(0)$ & \\
\hline Minimally invasive & No & 150(53.2) & 74 & 21 & 7 & 20 & 1 & 2 & 6 & \\
\hline procedure & Yes & 0 & 1 & 0 & 0 & 1 & 0 & 0 & 0 & \\
\hline Sclerectomy - & No & 150 & $75(26.6)$ & $21(7.4)$ & $7(2.5)$ & 20(7.1) & $1(0.4)$ & $2(0.7)$ & $6(2.1)$ & \\
\hline Viscocanalostomy & Yes & $0(0)$ & $0(0)$ & $0(0)$ & $0(0)$ & $1(100)$ & $0(0)$ & $0(0)$ & $0(0)$ & \\
\hline & No & $124(51.7)$ & $70(29.2)$ & $20(8.3)$ & $7(2.9)$ & $11(4.6)$ & $1(0.4)$ & $1(0.4)$ & $6(2.5)$ & \\
\hline & Yes & $26(60.5)$ & $5(11.6)$ & $1(2.3)$ & $0(0)$ & 10(23.3) & $0(0)$ & $1(2.3)$ & $0(0)$ & \\
\hline & No & $150(54.2)$ & $69(24.9)$ & $21(7.6)$ & $7(2.5)$ & $21(7.6)$ & $1(0.4)$ & $2(0.7)$ & $6(2.2)$ & \\
\hline & Yes & $0(0)$ & $6(100)$ & $0(0)$ & $0(0)$ & $0(0)$ & $0(0)$ & $0(0)$ & $0(0)$ & \\
\hline & No & 150(53) & $75(26.5)$ & $21(7.4)$ & $7(2.5)$ & $21(7.4)$ & $1(0.4)$ & $2(0.7)$ & $6(2.1)$ & Cannot be \\
\hline & Yes & $0(0)$ & $0(0)$ & $0(0)$ & $0(0)$ & $0(0)$ & $0(0)$ & $0(0)$ & $0(0)$ & calculated \\
\hline
\end{tabular}




\section{Cureus}

\begin{tabular}{|c|c|c|c|c|c|c|c|c|c|c|}
\hline \multirow{2}{*}{ Retinectomy } & No & $150(53.2)$ & $74(26.2)$ & $21(7.4)$ & $7(2.5)$ & $21(7.4)$ & $1(0.4)$ & $2(0.7)$ & $6(2.1)$ & \multirow{2}{*}{0.904} \\
\hline & Yes & $0(0)$ & $1(100)$ & $0(0)$ & $0(0)$ & $0(0)$ & $0(0)$ & $0(0)$ & $0(0)$ & \\
\hline \multirow{2}{*}{$\begin{array}{l}\text { Eye evisceration/ eye } \\
\text { removal }\end{array}$} & No & $150(53.4)$ & $74(26.3)$ & $21(7.5)$ & $7(2.5)$ & 20(7.1) & $1(0.4)$ & $2(0.7)$ & $6(2.1)$ & \multirow{2}{*}{0.464} \\
\hline & Yes & $0(0)$ & $1(50)$ & $0(0)$ & $0(0)$ & $1(50)$ & $0(0)$ & $0(0)$ & $0(0)$ & \\
\hline \multirow{2}{*}{$\begin{array}{l}\text { Phacoemulsification / } \\
\text { ECCE }\end{array}$} & No & $148(56.5)$ & $57(21.8)$ & $21(8)$ & $7(2.7)$ & $21(8)$ & $1(0.4)$ & $2(0.8)$ & $5(1.9)$ & \multirow{2}{*}{$<0.00$} \\
\hline & Yes & $2(9.5)$ & $18(85.7)$ & $0(0)$ & $0(0)$ & $0(0)$ & $0(0)$ & $0(0)$ & $1(4.8)$ & \\
\hline
\end{tabular}

TABLE 5: Distribution of treatment used for every glaucoma type

Extracapsular cataract extraction (ECCE)

\section{Discussion}

The present study demonstrates the glaucoma profile in patients who presented to KAMC in Jeddah. In addition, we analyzed the pattern of glaucoma among the patients to estimate the prevalence of different types of glaucoma, comorbidities, and clinical characteristics using internationally recognized glaucoma definitions.

No statistically significant difference was noted between males and females in our study as $53 \%$ of the sample were female compared to $47 \%$ males $(\mathrm{P}$-value $=0.087$ ). This contrasts with a local study which showed a significant difference between genders with a female predominance as $59 \%$ of their sample were females (p-value < 0.0001) [10]. Furthermore, we found that most patients had bilateral disease compared to either right or left eye involvement reaching statistical significance ( $p$-value $<0.001$ ). This finding is in line with other studies which showed a significantly greater proportion of bilateral involvement in patients with glaucoma. Moreover, a study done in Saudi Arabia supports our finding where it showed a difference between the two genders - females were 729 (59\%), and males were 507 (41\%) reaching clinical significance $(\mathrm{p}<.0001)$ with $816(66 \%)$ suffering bilateral disease and $420(34 \%)$ suffering unilateral disease $(\mathrm{p}<0.0001)$ [10].

\section{Types}

Our study showed that POAG is the predominant subtype, followed by secondary glaucoma types, childhood glaucoma, and PACG. The results are consistent with studies that have been conducted in western countries which reported POAG to be more prevalent (89.0\%) than PACG [2]. However, other studies from eastern countries with a high population size reported PACG is more prevalent than primary POAG [11]. Moreover, the Vellore Eye Study (VES) was one of the first studies emphasizing the high burden of angle closure in the Asian population with a prevalence of $10.3 \%$ of either occludable angles or angle-closure [12]. Furthermore, a study conducted in Oman reported the prevalence of POAG as 63.5\% and PACG as 12\% [13]. The low prevalence of closed-angle or narrow-angle glaucoma in their study might be because non-glaucoma specialists tend not to use the gonioscopy routinely to measure the angle. Secondary glaucoma represented $26.5 \%$ of the sample. These subtypes result from other pathological, surgical, or traumatic eye lesions. The prevalence of diabetes mellitus in Saudi Arabia contributes to the high incidence of proliferative diabetic retinopathy, which results in the increased prevalence of neovascular glaucoma (44.9\%) among the other secondary glaucoma types.

\section{Comorbidities}

Multiple studies have shown hypertension to be among the most common comorbid conditions with glaucoma, consistent with our findings $[14,15]$. However, approximately $61 \%$ of our sample had reported hypertension; other local and global studies have shown a much lower prevalence of hypertension at $35 \%$ and $37 \%$, respectively $[14,15]$. The significance of this association is controversial as the literature provides conflicting reports attributed to differences in the ethnic background of the samples being studied since populations of Asian, African, and Caucasian descent have a different prevalence of primary open-angle glaucoma and normal-tension glaucoma $[14,16]$. Two mechanisms are postulated to explain the relationship between hypertension and open-angle glaucoma. The first is that increased arterial pressure will cause hardening and atherosclerotic changes in the retinal vasculature with subsequent arteriolar narrowing and elevated resistance, which eventually compromises the adequacy of perfusion to the optic disc $[14,17,18]$. The other mechanism is related to the use of medications to lower blood pressure that might trigger episodes of systemic hypotension, which results in transient reductions in ocular blood supply $[14,19,20]$.

Another common comorbidity in our sample was diabetes mellitus, as seen in $58 \%$ of patients, which is higher than local studies in Riyadh and Qassim, which reported a prevalence of $14.9 \%$ and $32.8 \%$, respectively $[4,15]$. The mechanism by which diabetes is linked to glaucoma is believed to arise from 
impaired autoregulation of retinal and elevated predilection of retinal ganglion cells to programmed cell death $[14,21]$. The significance of the association between diabetes and glaucoma has been supported by some studies, whereas other articles have failed to demonstrate any significant association [14,22].

Dyslipidemia is among the comorbidities commonly associated with glaucoma and was seen in approximately $33.6 \%$ of our sample. This finding is similar to other global studies but higher than local reports $[14,15]$. However, several large population studies have shown that dyslipidemia was not significantly related to glaucoma and was negatively associated with the condition. Moreover, statin drugs used to lower cholesterol levels are hypothesized to positively reduce glaucomatous changes [23,24]. On the other hand, several studies have found glaucoma is associated with a higher prevalence of hyperlipidemia $[14,25]$. Furthermore, there are reports of increased risk of glaucoma in patients taking high doses of statin medications [25].

\section{Visual acuity}

Our study reported and categorized the best-corrected visual acuity based on the severity of visual impairment. Each category had an equal distribution between the right and left eye. A majority of the patients in our study had a functional vision that was distributed between patients who had a near-normal vision (19.22\%) and normal vision (16.01\%). However, $26.87 \%$ of the patients had moderate visual impairment. These findings are comparable to a local study that included 124 glaucoma cases which showed that most patients reported mild to no visual impairment (86.3\%), which was defined as visual acuity equal to or better than 6/18 [4]. On the other hand, moderate visual impairment was noted in $12.1 \%$ of the cases, which was defined as visual acuity worse than $6 / 18$ but better or equal to $6 / 60$ [4].

\section{Limitations}

This study was limited by multiple factors, including its small sample size and the retrospective singlecenter design, limiting the generalizability of results. Moreover, limited documentation in the clinical records is another shortcoming since multiple data were missing. Therefore, population-based studies with larger sample sizes are warranted to delineate better the prevalence and types of glaucoma among the Saudi population.

\section{Conclusions}

Primary open-angle glaucoma was the most common glaucoma subtype affecting half of the patients included in this study. Secondary glaucomas were the second most common, and the majority of cases were found to be neovascular glaucoma. In addition, hypertension and diabetes were the most common reported comorbidities seen in over half the patients. Moreover, a significantly higher proportion of patients had bilateral disease compared to unilateral.

\section{Additional Information \\ Disclosures}

Human subjects: Consent was obtained or waived by all participants in this study. Institutional Review Board (IRB) issued approval JED-21-427780-3866. After reviewing your submitted research proposal/protocol and related documents, the IRB has APPROVED the submission. The approval includes the following related documents: Document/ title version Date Research Proposal 0126 January 2021 Data Collection 0126 January 2021 The approval of the research study is valid for 1 year from the above approval to expiration date. Terms of Approval: • Annual Reports: An Annual report must be submitted for approval to avoid termination/suspension of your research. • Financial report: If your study is funded project, details financial report should be submitted with the scientific report. • Final Report: After completion of the study, a final report must be forwarded to the IRB. $\bullet$ Retention of original data: The PI is responsible for the storage and retention of original data pertaining to the project for a minimum of five years. $\bullet$ Reporting of adverse events or unanticipated problems: The PI is responsible to report any serious or unexpected adverse events or unanticipated problems, which could involve any risk to participants or others, or any event on incidents that may have impact on the research or participants. • Biological samples: No biological samples to be shipped out of the Kingdom of Saudi Arabia without prior IRB approval. • Participant incentives: No financial compensation or gifts to be given to participants without prior IRB approval. $\bullet$ Storage of biological samples: All biological samples collected for the purpose of this research must be stored in the KAIMRC related repository. - You will need to resubmit the proposal to the IRB for review and re-approval before implementing any changes to the approved proposal. $\bullet$ It is possible that the IRB may decide that the proposed new changes may exclude the proposal from being accepted for exempt review. $\bullet$ It is your responsibility to safely store the data collected. $\bullet$ Please note that phone-based surveys are not permitted. $\bullet$ If your approved proposal requires access to Bestcare, please write to the IRB informing them of the name of the designated data collector and exactly define the period requested for collecting data. Do not start the data collection until an approval memo is issued from the IRB giving permission to that collector to start accessing Bestcare for the duration of the project and after signing a confidentiality agreement. Animal subjects: All authors have confirmed that this study did not involve animal subjects or tissue. Conflicts of interest: In compliance with the ICMJE uniform disclosure form, all authors declare the following: 
Payment/services info: All authors have declared that no financial support was received from any organization for the submitted work. Financial relationships: All authors have declared that they have no financial relationships at present or within the previous three years with any organizations that might have an interest in the submitted work. Other relationships: All authors have declared that there are no other relationships or activities that could appear to have influenced the submitted work.

\section{References}

1. WHO | Glaucoma is second leading cause of blindness globally . (2021). Accessed: April 16, 2021 : https://www.who.int/bulletin/volumes/82/11/feature1104/en/..

2. Quigley HA, Broman AT: The number of people with glaucoma worldwide in 2010 and 2020 . Br J Ophthalmol. 2006, 90:262-267. 10.1136/bjo.2005.081224

3. Kreft D, Doblhammer G, Guthoff RF, Frech S: Prevalence, incidence, and risk factors of primary open-angle glaucoma - a cohort study based on longitudinal data from a German public health insurance. BMC Public Health. 2019, 19:851. 10.1186/s12889-019-6935-6

4. Khandekar R, Chauhan D, Yasir ZH, Al-Zobidi M, Judaibi R, Edward DP: The prevalence and determinants of glaucoma among 40 years and older Saudi residents in the Riyadh Governorate (except the Capital) - A community based survey. Saudi J Ophthalmol. 2019, 33:332-337. 10.1016/j.sjopt.2019.02.006

5. McMonnies CW: Glaucoma history and risk factors. J Optom. 2017, 10:71-78. 10.1016/j.optom.2016.02.003

6. Tham YC, Li X, Wong TY, Quigley HA, Aung T, Cheng CY: Global prevalence of glaucoma and projections of glaucoma burden through 2040: a systematic review and meta-analysis. Ophthalmology. 2014, 121:20812090. 10.1016/j.ophtha.2014.05.013

7. Bagabas N, Ghazali W, Mukhtar M, et al.: Prevalence of glaucoma in patients with obstructive sleep apnea . J Epidemiol Glob Health. 2019, 9:198-203. 10.2991/jegh.k.190816.001

8. Al-Shaaln FF, Bakrman MA, Ibrahim AM, Aljoudi AS: Prevalence and causes of visual impairment among Saudi adults attending primary health care centers in northern Saudi Arabia. Ann Saudi Med. 2011, 31:473480. 10.4103/0256-4947.84624

9. Colenbrander A: Visual Standards Aspects and Ranges of Vision Loss with Emphasis on Population Surveys . International Council of Ophthalmology, Sydney; 2002.

10. Al Obeidan SA, Dewedar A, Osman EA, Mousa A: The profile of glaucoma in a Tertiary Ophthalmic University Center in Riyadh, Saudi Arabia. Saudi J Ophthalmol. 2011, 25:373-379. 10.1016/j.sjopt.2011.09.001

11. Foster PJ, Johnson GJ: Glaucoma in China: how big is the problem? . Br J Ophthalmol. 2001, 85:1277-1282. 10.1136/bjo.85.11.1277

12. Foster PJ: The epidemiology of primary angle closure and associated glaucomatous optic neuropathy . Semin Ophthalmol. 2002, 17:50-58. 10.1076/soph.17.2.50.14718

13. Khandekarl R, Zutshi R: Glaucoma in Oman: a review. J Glaucoma. 2006, 15:271-273. 10.1097/01.ijg.0000212206.79899.cc

14. Lee SH, Kim GA, Lee W, Bae HW, Seong GJ, Kim CY: Vascular and metabolic comorbidities in open-angle glaucoma with low- and high-teen intraocular pressure: a cross-sectional study from South Korea. Acta Ophthalmol. 2017, 95:564-574. 10.1111/aos.13487

15. Newman-Casey PA, Talwar N, Nan B, Musch DC, Stein JD: The relationship between components of metabolic syndrome and open-angle glaucoma. Ophthalmology. 2011, 118:1318-1326. 10.1016/j.ophtha.2010.11.022

16. Cho HK, Kee C: Population-based glaucoma prevalence studies in Asians. Surv Ophthalmol. 2014, 59:434447. 10.1016/j.survophthal.2013.09.003

17. Wong TY, Mitchell P: The eye in hypertension. Lancet. 2007, 369:425-435. 10.1016/S0140-6736(07)60198-6

18. Ramdas WD, Wolfs RC, Hofman A, de Jong PT, Vingerling JR, Jansonius NM: Ocular perfusion pressure and the incidence of glaucoma: real effect or artifact? The Rotterdam Study. Invest Ophthalmol Vis Sci. 2011, 52:6875-6881. 10.1167/iovs.11-7376

19. Hayreh SS, Zimmerman MB, Podhajsky P, Alward WL: Nocturnal arterial hypotension and its role in optic nerve head and ocular ischemic disorders. Am J Ophthalmol. 1994, 117:603-624. 10.1016/s00029394(14)70067-4

20. Hayreh SS, Podhajsky P, Zimmerman MB: Role of nocturnal arterial hypotension in optic nerve head ischemic disorders. Ophthalmologica. 1999, 213:76-96. 10.1159/000027399

21. Kanamori A, Nakamura M, Mukuno H, Maeda H, Negi A: Diabetes has an additive effect on neural apoptosis in rat retina with chronically elevated intraocular pressure. Curr Eye Res. 2004, 28:47-54. 10.1076/ceyr.28.1.47.23487

22. Zhao D, Cho J, Kim MH, Friedman DS, Guallar E: Diabetes, fasting glucose, and the risk of glaucoma: a meta-analysis. Ophthalmology. 2015, 122:72-78. 10.1016/j.ophtha.2014.07.051

23. Kim M, Jeoung JW, Park KH, Oh WH, Choi HJ, Kim DM: Metabolic syndrome as a risk factor in normaltension glaucoma. Acta Ophthalmol. 2014, 92:637-643. 10.1111/aos.12434

24. Stein JD, Newman-Casey PA, Talwar N, Nan B, Richards JE, Musch DC: The relationship between statin use and open-angle glaucoma. Ophthalmology. 2012, 119:2074-2081. 10.1016/j.ophtha.2012.04.029

25. Chen HY, Hsu SY, Chang YC, Lin CC, Sung FC, Chen WC, Kao CH: Association between statin use and openangle glaucoma in hyperlipidemia patients: a Taiwanese population-based case-control study. Medicine (Baltimore). 2015, 94:e2018. 10.1097/MD.0000000000002018 